\title{
Human Bone Marrow Stromal Cells can Differentiate to a Retinal Pigment Epithelial Phenotype when Co-Cultured with Pig Retinal Pigment Epithelium using a Transwell System
}

\author{
Ping Duan ${ }^{a, b}$ Haiwei Xu ${ }^{a, b}$ Yuxiao Zeng ${ }^{a, b}$ Yi Wang ${ }^{a, b} \quad$ Zheng Qin Yin ${ }^{a, b}$
}

aSouthwest Eye Hospital, Southwest Hospital, Third Military Medical University, Chongqing, China;

${ }^{b}$ Key Lab of Visual Damage and Regeneration \& Restoration of Chongqing, Chongqing, China

\section{Key Words}

Retinal pigment epithelial cells $\cdot$ Bone marrow stromal cells $\cdot$ Co-culture $\cdot$ Differentiation Transwell system

\begin{abstract}
Background: There is an increasing interest in generating retinal pigment epithelial (RPE) cells from stem cells for therapy against degenerative eye diseases. Human bone marrow stromal cells (hBMSCs) can be induced to express retinal neuron-specific markers when co-cultured with retinal neurons, however, whether hBMSCs can differentiate into RPE-like cells in a co-culture system has not been clarified. Methods: The induction of hBMSCs into RPE-like cells was performed by combining hBMSCs and pig RPE cells in a transwell system. The biomarkers of hBMSCs-derived RPE cells were determined by quantitative RT-PCR and immunofluorescence. The function of induced cells was assayed by ELISA for secretion of neurotrophic factors. Results: Intracellular pigment granules and many RPE markers existed in hBMSCs-derived RPE cells after co-culturing with pig RPE cells for 14 days. Typical RPE functions, such as phagocytosis of photoreceptor outer segments and secretion of the trophic factors, brain-derived neurotrophic factor (BDNF) and glia-derived neurotrophic factor (GDNF), were observed in these induced cells. Conclusion: hBMSCs can be induced toward functional RPE cells simply by transwell-based co-culture with RPE cells.
\end{abstract}

Copyright (C 2013 S. Karger AG, Basel

Prof. Yi Wang, and Prof. Zheng Qin Yin

Southwest Eye Hospital, Southwest Hospital, Third Military Medical University Chongqing, 400038 (China)

Tel. +86-23-68754803, Fax +86-23-68754401

E-Mail wangyieye@yahoo.com.cn; E-Mail qinzyin@yahoo.com.cn 


\section{Cellular Physiology and Biochemistry}

Cell Physiol Biochem 2013;31:601-613

DOI: $10.1159 / 000350080$

Published onIIne: VVay 02, 2013

(C) 2013 S. Karger AG, Basel

www.karger.com/cpb

602

Duan/Xu/Zeng/Wang/Yin: Transwell Co-Culture Induces RPE Differentiation of BMSCs

\section{Introduction}

Age-related macular degeneration (AMD) is one of the most prevalent causes of blindness in the senescent populations of many countries [1-3]. In this retinal degenerative disease, the degeneration and loss of the retinal pigment epithelium (RPE) at the posterior pole results in the degeneration of photoceptors [4]. However, obtaining a sufficient number of donor RPE cells that have a low risk of immunological rejection and tumorigenesis still remains a significant barrier for effective therapy [5].Stem-cell-based therapeutic approaches represent promising approaches to the treatment of retinal degeneration and the restoration of vision [6-8]. We reported previously that by transfecting Noggin gene, human bone marrow stromal cells (hBMSCs) can trans-differentiate into photoreceptor cells [9]. Recently, it has been reported that by using a versatile floating culture in serum-free and growth-factor-reduced medium, mouse embryonic stem cells (mESCs) and human embryonic stem cells (hESCs) can self-form into a two-walled optic cup $[10,11]$. This confirmed that ESCs have the capacity to differentiate into all types of eye cells, including RPE cells. Using a hESC-derived RPE, Schwartz et al started two prospective clinical trials with patients suffering from Stargardt's macular dystrophy or dry age-related macular degeneration, and demonstrated that hESCderived RPE cells showed no signs of hyperproliferation, tumorigenicity, or ectopic tissue formation after 4 months [12].

Compared with ESCs that are currently used clinically, adult stem cells can be isolated from individual patients and avoid the risk of immunological rejection, and the committed differentiation capacity restrains the possibility of tumor formation. By expansion in an in vitro system, adult stem cells can provide enough seed cells for cell transplantation $[13,14]$. Furthermore, adult stem cells are attractive candidates for cellular therapies, due to the distinct advantages of autologous availability and any ethical concerns associated with other stem cells [15]. Recently, it was shown that adipose tissue-derived mesenchymal stromal cells have the differentiation potential to become RPE-like cells $[16,17]$. Similarly, using a direct cell-cell contact co-culture system, human bone marrow stromal cells (hBMSCs) can be induced to differentiate into RPE-like cells and have been proposed as a potential cellular source of stem cells for treating degenerative diseases $[18,19]$, while the function of these hBMSCs-derived RPE cells and their differentiation mechanisms have not been clarified.

It is widely accepted that the fate of adult stem cells is determined by the microenvironment or 'niche' surrounding them. The microenvironment consists of many factors critically involved in the differentiation of stem cells [20,21]. Replicating the local environment offers a potentially successful way of mimicking the physiological conditions necessary to induce BMSC differentiation [22, 23]. Our previous results demonstrated that BMSCs could be induced to express retinal neuron-specific phenotypic markers in response to retinal neuron co-culture using a transwell system [24]. Nevertheless, whether this co-culture system can effectively induce hBMSCs to differentiate into RPE-like cells remains unclear. We used a transwell-based BMSC/RPE co-culture system to mimic part of the microenvironment for RPE differentiation in order to determine whether this would facilitate a RPElineage differentiation of hBMSCs. Our results show a positive effect of directing hBMSCs differentiation towards a RPE-like cell phenotype.

\section{Materials and Methods}

Isolation and culture of human BMSCs, human RPE and pig RPE

Reagents were from Sigma (St. Louis, MO) unless stated otherwise. Human BMSCs (hBMSCs) were kindly gifted by Dr Dai (Department of Orthopedics, Southwest Hospital, Third Military Medical University, Chongqing, 400038) [25] and were isolated from the marrow of the iliac crest during routine surgical procedures. The Ethics Committee of Southwest Hospital specifically approved this study. All participants have provided their informed consents to participate in this study. The marrow was diluted with phosphate buffer solution ( $\mathrm{pH} 7.3$ ) and loaded over a Ficoll solution with a density of $1.073 \mathrm{~g} / \mathrm{ml}$. The mixture was 


\section{Cellular Physiology and Biochemistry}

Cell Physiol Biochem 2013;31:601-613

DOI: $10.1159 / 000350080$

Published online: IVay 02, 2013

(C) 2013 S. Karger AG, Basel

www.karger.com/cpb

Duan/Xu/Zeng/Wang/Yin: Transwell Co-Culture Induces RPE Differentiation of BMSCs

centrifuged at $900 \mathrm{~g}$ for $20 \mathrm{~min}$, and then the nucleated cells at the interface collected and washed with PBS by centrifugation at $700 \mathrm{~g}$ for $10 \mathrm{~min}$ at room temperature [25]. The precipitate was re-suspended in MSC culture medium, consisting of DMEM/F12 (Hyclone, Logan, USA) supplemented with 10\% fetal bovine serum (FBS, Hyclone).

Enucleated porcine eyes from a slaughterhouse (Zhong Yu slaughterhouse of Chongqing) pigs were used for the preparation of porcine RPE cells. We have obtained permission from this slaughterhouse to use these animal parts. For this purpose, the anterior segment, vitreous content and retina were removed. The remaining scleral/choroidal/RPE compound of the eyecup was filled with trypsin/sodium EDTA solution ( $0.5 \mathrm{~g} / \mathrm{L}$ porcine trypsin plus $0.5 \mathrm{~g} / \mathrm{L}$ sodium EDTA; Hyclone) for $10 \mathrm{~min}$ and gently agitated. Digestion was stopped by adding culture medium then pouring off the cell suspension. RPE cells were grown in DMEM/ F12 supplemented with $10 \%$ FBS and antibiotics (penicillin $100 \mathrm{U} / \mathrm{ml}$, streptomycin $100 \mu \mathrm{g} / \mathrm{ml}$ ) at $37^{\circ} \mathrm{C}$ in a humidified atmosphere with $5 \% \mathrm{CO}_{2}$. Human RPE cells were generated from the discard material of enucleated human donor eyes. The preparation protocol was the same as the one applied for porcine RPE cells [17]. The study was conducted in accordance with the tenets of the World Medical Association's Declaration of Helsinki on ethical principles for medical research.

The preparation of RPE-conditioned medium was according to another study [17] with some minor modifications. Briefly, culture medium was conditioned for 1 week with porcine RPE cells, harvested and centrifuged sharply at $12000 \mathrm{~g}$ for $10 \mathrm{~min}$ to remove solid particles.

\section{FACS of hBMSCS}

Flow cytometry analysis was performed on a BD FACS Aria Flow Cytometer (BD Biosciences, San Diego, CA). Confluent hBMSCs after the third passage were trypsinized and stained using fluorescein isothiocyanate-labeled antibodies against CD14, CD45, and CD34, or phycoerythrin-labeled CD105, CD90, and CD73 (all from eBioscience, San Diego, CA). Negative control immunofuorescence experiments were performed in parallel with unrelated antibodies.

\section{Differentiation properties of $h B M S C s$}

After the eighth passage, hBMSCs were induced to undergo osteogenic, adipogenic, or chondrogenic differentiation as previously described [22]. To stimulate osteogenic differentiation, cells were treated with osteogenic medium for three weeks. Adipogenic stimulation medium consisted of DMEM-LG supplemented with $10 \%$ FBS, $50 \mu \mathrm{g} / \mathrm{ml}$ ascorbate- 2 phosphate, $10^{-7} \mathrm{M}$ dexamethasone, and $10 \mathrm{mM} \beta$-glycerophosphate (all from Sigma). Cells were cultured for three weeks, and were subsequently fixed with $4 \%$ formaldehyde and stained with Oil-red 0 (Sigma).To evaluate the mineralized matrix, differentiated BMSCs were treated with $2 \%$ silver nitrate (Sigma) under a UV lamp for $1 \mathrm{~h}$, fixed with $2.5 \%$ sodium thiosulfate (Sigma) for 5 min, washed with $\mathrm{dH}_{2} \mathrm{O}$, and then counterstained with $1 \%$ alizarin red (Sigma). In order to induce chondrogenesis, cells were cultured as a high-density pellet $\left(2.5 \times 10^{5}\right.$ cells/pellet $)$ in DMEM-LG serumfree medium supplemented with $10^{-7} \mathrm{M}$ dexamethasone, $40 \mu \mathrm{g} / \mathrm{ml}$ L-proline, $100 \mu \mathrm{g} / \mathrm{ml}$ sodium pyruvate, $1 \%$ ITS-premix, and $10 \mathrm{ng} / \mathrm{ml}$ transforming growth factor- $\beta 3$ (TGF- $\beta 3$ ) (R\&D Systems, Minneapolis, MN) for four weeks. The extracellular matrix in the chondrocyte-like beads and the pellets were embedded in paraffin, cut into histological sections and stained with alcian blue (Sigma).

\section{Co-culture system of $h B M S C$ s and pig RPE}

Transwell chambers (Millipore, USA) were employed in the co-culture induction system. The upper and lower cultures were separated by $1 \mu \mathrm{m}$ pore size polyvinylpyrrolidone-free polycarbonate filters. Briefly, the lower compartment of the chamber was loaded with hBMSCs $\left(1 \times 10^{5}\right.$ cells/well $)$ and the upper chamber was loaded with adult pig RPE cells $\left(1 \times 10^{5}\right.$ cells/well $)$. The chamber was cultured in a humidified incubator with $5 \% \mathrm{CO}_{2}$ at $37^{\circ} \mathrm{C}$ for 14 days. The medium was changed twice a week.

\section{Measurement of melanin content}

Melanin content was determined according to the method of Huang et al. [26] with slight modifications. The cells $\left(1 \times 10^{5}\right.$ cells/well $)$ were seeded in a 24 -well plate and cultured overnight. Then the cells were washed with phosphate-buffered saline, and were lysed with $250 \mathrm{ml}$ of $0.85 \mathrm{~N} \mathrm{KOH}$ and the solution transferred to a 96-well plate. The relative melanin content was estimated by the amount of light absorbance at a wavelength of $405 \mathrm{~nm}$. 


\section{Cellular Physiology and Biochemistry}

Cell Physiol Biochem 2013;31:601-613

DOI: $10.1159 / 000350080$

Publisned online: $v$ vay, 2013

www.karger.com/cpb

Table 1. The primer sequences used for real-time PCR analysis of RPE-specific genes in hBMSCs-derived RPE cells

\begin{tabular}{|c|c|c|}
\hline Gene & Primer sequences $\left(5^{\prime}-3^{\prime}\right)$ & $\begin{array}{l}\text { Product length } \\
\text { (bp) }\end{array}$ \\
\hline \multirow[t]{2}{*}{ MITF } & CCCAGGCCCAGCTACCTTCC(F) & 104 \\
\hline & GGCACGATCCCCGATTCGGAC(R) & \\
\hline \multirow[t]{2}{*}{ оTX2 } & ACCCGGTAGTGTGTCCCGCT(F) & 208 \\
\hline & TCGCCGCTCTCTTCCAGGGT(R) & \\
\hline \multirow[t]{2}{*}{ tyrosinase } & TGCCAACGATCCTATCTTCC(F) & 52 \\
\hline & GACACAGCAAGCTCACAAGC(R) & \\
\hline \multirow[t]{2}{*}{ RPE65 } & GTCCTCGCCGCTCACAGCTC(F) & 137 \\
\hline & GCAGGAGGGCTTGCCCATCAAA(R) & \\
\hline \multirow[t]{2}{*}{ Bestrophin } & TCCCACCTGCCTAGTCGCCA(F) & 186 \\
\hline & TTGTAGATGCTGCCCCGCCA(R) & \\
\hline \multirow[t]{2}{*}{ PEDF } & GGGAGCGGAGCAGCGAACAG(F) & 248 \\
\hline & GGTCCAAGCGAGGGTTGCCC(R) & \\
\hline \multirow[t]{2}{*}{ PMEL17 } & TGCCTGTGCCTGGGATTCTTCTCA(F) & 194 \\
\hline & GATGCGGGGTAGACGCAGCC(R) & \\
\hline \multirow[t]{2}{*}{ CRALBP } & CCCCGCCACACCTTGCAGAA(F) & 191 \\
\hline & TTCCGTGCGCGGATGAAGCG(R) & \\
\hline \multirow[t]{2}{*}{ PAX6 } & CCGTGGCTCGGCCTCATTTC(F) & 107 \\
\hline & ACCGCTCCTCACTGGCCCATTA(R) & \\
\hline \multirow[t]{2}{*}{ GAPDH } & AGCCTCCCGCTTCGCTCTCT(F) & 141 \\
\hline & CCAGGCGCCCAATACGACCA(R) & \\
\hline
\end{tabular}

Electron microscopy (EM)

In vitro hBMSC-derived RPE cells grown on the membrane of transwell were fixed with $2.5 \%$ glutaraldehyde in $0.1 \mathrm{M}$ cacodylate buffer ( $\mathrm{pH} 7.4$ ) for $24 \mathrm{~h}$ and then processed according to the procedure described in another study [27].

\section{Quantitative RT-PCR}

Total RNA was isolated using TRIzol reagent (Invitrogen) according to the manufacturer's instructions. After a reverse transcription reaction, real-time PCR was performed with an ABI 7900HT system using

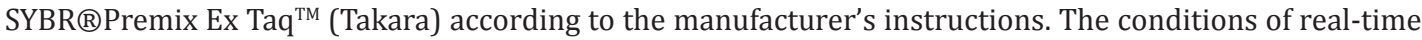
PCR were as follows: 40 cycles of $94^{\circ} \mathrm{C}$ for $10 \mathrm{sec}$, and $60^{\circ} \mathrm{C}$ for $30 \mathrm{sec}$. A melting stage was added to the end of the amplification procedure. There was no non-specific amplification as determined by the melting curve. GAPDH was used as the internal control. The following RPE-specific markers-MITF, OTX2, bestrophin, tyrosinase, bestrophin, PMEL17, RPE65, PEDF and CRALBP were analyzed; the primer sequences used for this analysis are listed in Table 1.

\section{Immunofluorescence}

Immunocytologic analysis was performed according our previous methods [24]. In brief, the cells were fixed with 4\% paraformaldehyde for 20 min (Sigma-Alrich Chemie GmbH, Taufkirchen, Germany), permeabilized with $0.3 \%$ Triton X-100 for 5 min at room temperature and protein blocked with $10 \%$ sheep serum at $37^{\circ} \mathrm{C}$ for $30 \mathrm{~min}$. The following primary antibodies were used: CRALBP (Thermo, 1: 500), RPE65 (Millipore, 1:500) and zonula occludens-1 (ZO-1) (Invitrogen, 1:400) at $4^{\circ} \mathrm{C}$ overnight. Isotype control $\mathrm{Ab}$ was used at the same concentrations as the primary Ab. A Cy3-conjugated secondary antibody (Santa Cruz, CA) was incubated at room temperature for $1 \mathrm{~h}$. hBMSCs without any treatment served as negative control, and mature porcine RPE cells as a positive control. 


\section{Cellular Physiology and Biochemistry}

Cell Physiol Biochem 2013;31:601-613

DOI: $10.1159 / 000350080$

Published oniıne: IVay 02, 2013

C) 2013 S. Karger AG, Basel

www.karger.com/cpb

605

Duan/Xu/Zeng/Wang/Yin: Transwell Co-Culture Induces RPE Differentiation of BMSCs

Phagocytosis of photoreceptor outer segments isolated from porcine eyes

Retinas from freshly slaughtered porcine eyes were dissected free from the RPE under sterile conditions and the photoreceptor outer segments (POSs) isolated using a continuous sucrose gradient as previously described [28]. The POS pellet was resuspended in $1 \mathrm{ml}$ of $10 \mathrm{mM}$ sodium phosphate, and then labeled with FITC (Invitrogen) in $0.1 \mathrm{M}$ sodium bicarbonate/5\% sucrose in a light-tight microcentrifuge tube for $1 \mathrm{~h}$ at room temperature. Labeled POSs were then washed and resuspended in RPE culture medium containing $5 \%$ sucrose. POSs were then seeded onto cells at $1 \times 10^{7} \mathrm{POS} / \mathrm{ml}$. Cells were incubated at $37^{\circ} \mathrm{C}$ in $5 \% \mathrm{CO}_{2}$ for $24 \mathrm{~h}$. They were then treated for $10 \mathrm{~min}$ with trypan blue to remove external fluorescence and washed. The cultures were examined with combined confocal microscopy (Leica TCS SP2, Leica, Wetzlar, Germany) and DIC to determine whether the FITC-labeled POS debris had been phagocytosed by the cells. To quantify the levels of phagocytosis, images were taken blind and the total number of fluorescent POS counted within the $60 \times$ magnification confocal field $(150 \mu \mathrm{m} \times 150 \mu \mathrm{m})$. Cluster of POS separated by more than $5 \mu \mathrm{m}$ was counted as separate entities.

\section{Western blotting}

Western blotting protocols were according to a previous report[29]. Briefly, cell lysates were separated by SDS/PAGE in 10\% Tris-glycine gels (Invitrogen) and transferred to an NC membrane. To determine expression levels of MERTK and $\alpha \mathrm{V} \beta 5$ Integrin, the monoclonal anti-MERTK antibody (diluted with 5\% BSA to 1: 50, Abcam, Cambridge, UK) and anti- $\alpha$ V 35 Integrin antibody $(10 \mu \mathrm{g} / \mathrm{ml}$, Millipore, Germany) were used, respectively. Membranes were probed with horseradish peroxidase (HRP)-labeled anti-mouse secondary antibody (Cell Signaling, diluted with 5\% BSA to 1: 1500). The binding of antibodies were detected by enhanced chemiluminescence detection kit (ECL) (UK Amersham International plc). All Western blot exposures were in the linear range of detection. The intensities of the resulting bands were quantified by Quantity One software on a GS-800 densitometer (Bio-Rad).

ELISA for secretion of neurotrophic factors by RPE

hBMSCs, RPE cells and hBMSCs-derived RPE cells $\left(5 \times 10^{4}\right.$ cells) were plated in 24 -well plates. Three days later, conditioned medium was harvested and centrifuged to remove particulate matter and stored at $-20^{\circ} \mathrm{C}$ until analyzed. Quantification of brain-derived neurotrophic factor (BDNF) and glia-derived neurotrophic factor (GDNF) secreted into the medium was determined using a quantitative sandwich ELISA according to the manufacturer's instructions (R\&D Systems, Minneapolis, MN). Values for the conditioned medium samples were determined by comparison to a standard curve and corrected for cell number.

\section{Statistical analysis}

All data are presented as mean \pm S.D. unless otherwise specified. Statistical significance was calculated for two-sample comparisons by Student's t-test using SPSS 16.0 software. Statistical significance was analyzed for data from at least three independent experiments. $P$ values $\leq 0.05$ were defined as significant.

\section{Results}

Characterization of human bone marrow stromal cells

After cultured for two passages, stromal cells from bone marrow displayed typical hBMSCs characteristics as flow cytometry analyses revealed that hBMSCs were strongly positive for CD73, CD90 and CD105, but negative for CD14, CD45 and CD34 (Fig. 1).

\section{hBMSC potential for osteogenic, chondrogenic and adipogenic differentiation}

As shown in Fig. 1G, hBMSCs stained by alizarin red exhibited matrix mineralization formation after 21-days in culture. hBMSCs were also able to differentiate towards an adipose phenotype after culturing for 21 days with adipogenic medium (Fig. 1H; Oil-red 0 staining). In addition, the cells could also be induced towards a chondrogenic phenotype after four weeks in culture following the formation of a high-density pellet and a serumfree chondrogenic medium with TGF- $\beta 3$ (Fig. 1I, positive alcian blue staining). These results indicate that the hBMSCs have the properties of stromal and mesenchymal cells. 
Fig. 1. The characteristics and differentiation potential of hBMSCs. A-F, hBMSCs were cultured until the 8th passage and then labeled with monoclonal antibodies against CD73, CD90, CD105, CD14, CD45 and CD34, and analyzed by FACS ( $\mathrm{n}=3$ independent experiments). G, hBMSCs exhibited matrix mineralization formation after the addition of osteogenic induction medium and culturing for three weeks (alizarin red staining). H, hBMSCs exhibited adipose formation after the addition of adipogenic induction medium and culturing for three weeks (Oilred 0 staining). I, hBMSCs exhibited chondrogenesis after the addition of chondrogenic medium induction with TGF- $\beta 3$ and culturing for four weeks (alcian staining).

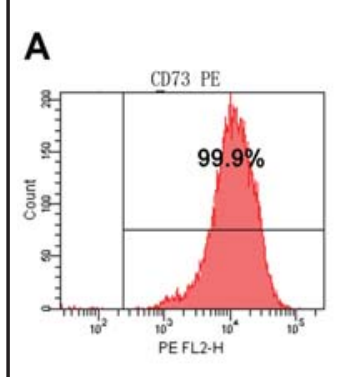

B
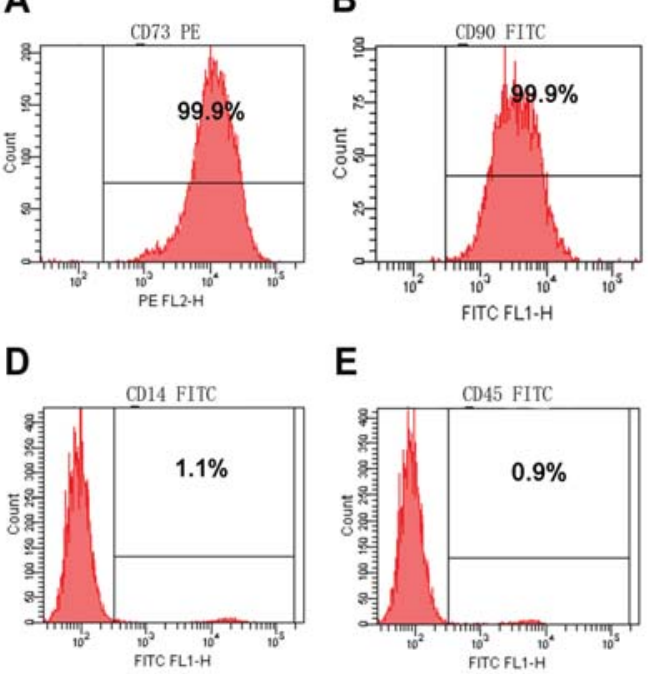

E
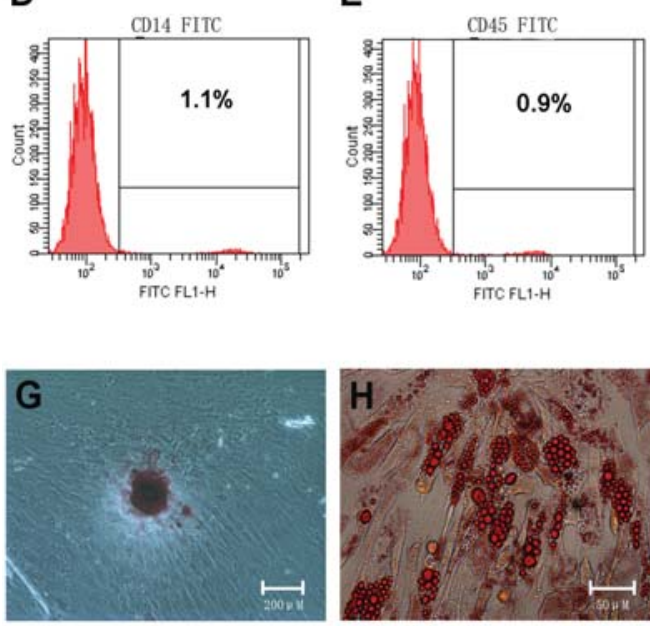

F

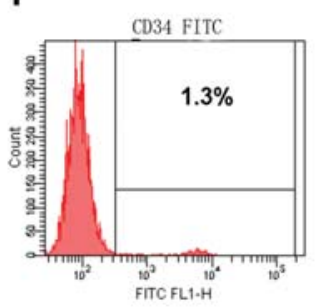

C
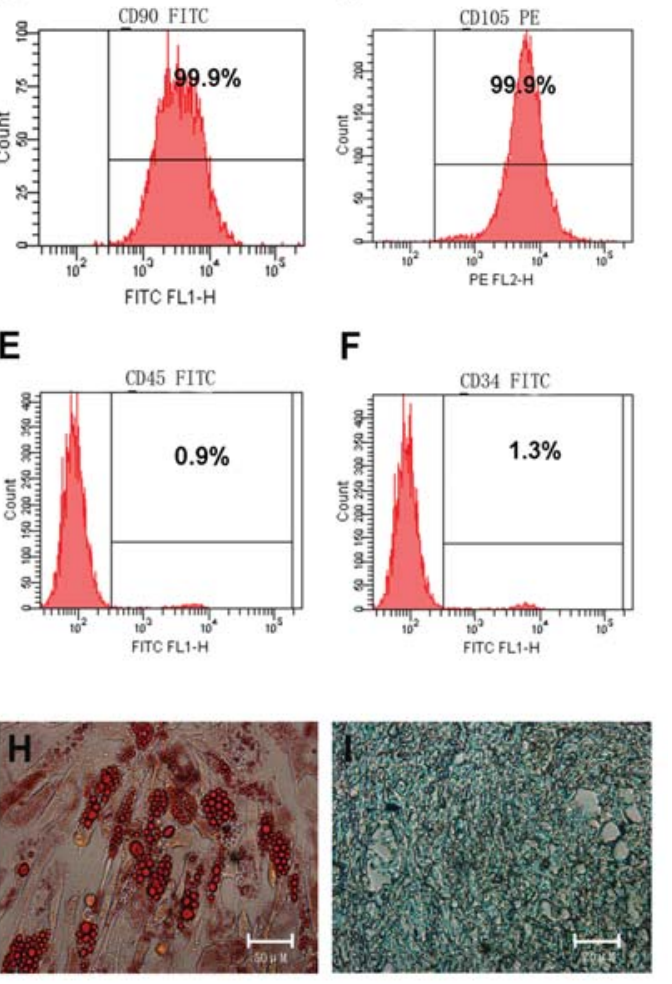

In vitro differentiation of hBMSCs toward a RPE phenotype

To induce hBMSCs (Fig. 2A) to undergo differentiation towards a RPE phenotype, we isolated pig RPE cells and employed a transwell co-culture system (adult pig RPE/hBMSC). After 7-day co-culture, some intracellular pigment granules were observed in hBMSCs (Fig. 2B), which had significantly increased by day 14 (Fig. 2C), at which point the amount of pigment granules was comparable to that seen in the primary isolated adult pig RPE cells (Fig. 2E). Notably, these hBMSC-derived RPE cells still contained many pigment granules after one passage (Fig. 2D). Statistical analysis showed that whereas after 7-day co-culture, the amount of intracellular pigment granules in hBMSC-derived RPE cells was obviously fewer than that in primary isolated adult pig RPE cells ( $\mathrm{n}=4, p \leq 0.01)$, after 14-day co-culture, the amount of intracellular pigment granules in hBMSC-derived RPE cells was comparable to that in primary isolated RPE cells (Fig. 2F). Besides, electron microscopy also revealed the presence of mature pigment granules (Fig. 2G), and furthermore, microvilli was clearly present in hBMSC-derived RPE cells after 14-day co-culture (Fig. 2H).

To confirm that the pigment granules seen in induced hBMSCs really developed in these cells, we used RPE-conditioned medium without melanosome secreted by RPE cells for induction of hBMSCs. As shown in Fig. 2 I, J and K, Similar with another study [30], after incubation in the RPE-conditioned medium for 7 days, the cytoplasmic pigment granules were seen in hBMSCs. After 14-day co-culture, the amount of pigment granules significantly increased, whereas was lower than that in hBMSCs after transwell-based co-culture with primary isolated RPE cells. These results suggest that the pigment granules seen in induced hBMSCs have indeed developed in these cells. However, in the transwell co-culture system, the melanosomes present in induced hBMSCs derive partly from secretion by RPE cells.

Pigmented cells express retinal pigment epithelium-specific genes and proteins

Various RPE-specific markers in hBMSC-derived RPE like cells were determined. These genes were significantly up-regulated; MITF ( 2-fold), OTX2 ( 4-fold), tyrosinase $(\sim 3.5$ - 


\section{Cellular Physiology \\ and Biochemistry}

Cell Physiol Biochem 2013;31:601-613

\begin{tabular}{l|l}
\hline DOI: $10.1159 / 000350080$ & (C) 2013 S. Karger AG, Basel
\end{tabular}

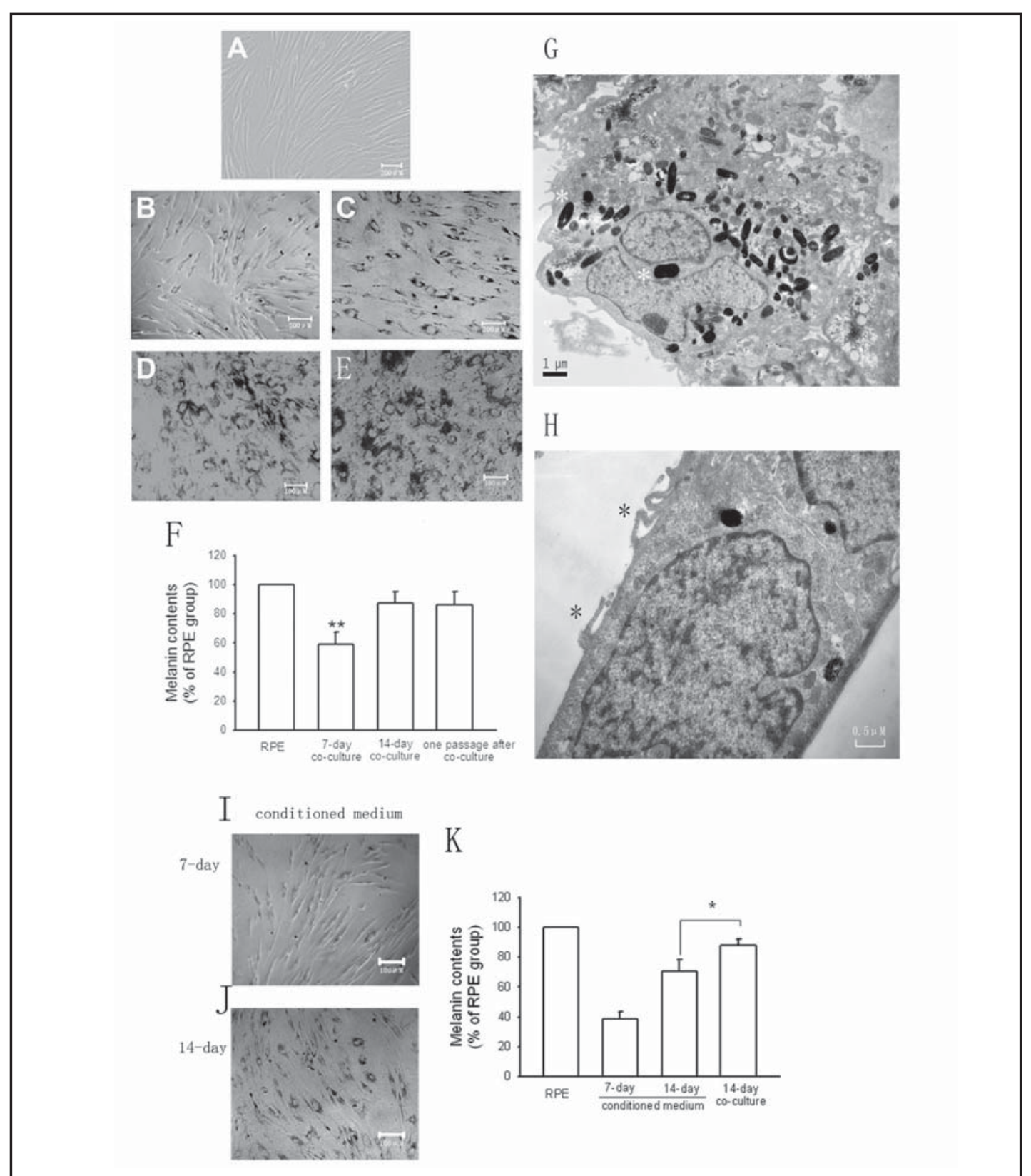

Fig. 2. Cell phenotypes of hBMSCs co-cultured with adult pig RPE cells in the transwell system. A, cultured hBMSCs prior to co-culturing in the transwell plates. B and C, intracellular pigment granules were seen in hBMSCs after 7 and 14 days of co-culturing respectively (inverted microscopic observations). D, pigment granules were still present in the after one passage. E, intracellular pigment granules in primary isolated adult pig RPE cells. F, statistical analysis of the relative amount of intracellular pigment granules in different cultures by measurement of melanin content (mean \pm S.D., $n=4$ independent experiments). **Significantly different from fresh RPE control, $\mathrm{P} \leq 0.01$. G, electron microscopy (EM) analysis of mature pigment granules (in an hBMSC-derived RPE cell following 14-day co-culture induction. H, apical villi (arrows) was present in hBMSC-derived RPE cell following 14-day co-culture induction analyzed by EM.I and J, intracellular pigment granules were seen in hBMSCs after 7- and 14-day culture with RPE conditioned medium, respectively. $\mathrm{K}$, statistical analysis of the relative amount of intracellular pigment granules in different cultures by measurement of melanin content (mean \pm S.D., $\mathrm{n}=4$ independent experiments). ${ }^{*} \mathrm{P}<0.05$.

fold), bestrophin ( 2-fold), PMEL17 ( 1.5-fold), RPE65 ( 2.5-fold), PEDF ( 4-fold) and CRALBP $(\sim 1.2$-fold $)$ after being co-cultured with adult pig RPE cells for 14 days compared 


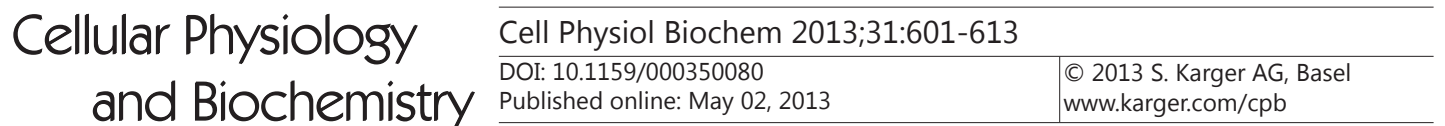 and Biochemistry $\frac{\text { Published online: Mnay 02, } 2013}{\text { Duan/Xu/Zeng/Wang/Yin: Transwell Co-Culture Induces RPE Differentiation of BMSCs }}$}

Fig. 3. Determination of RPE-specific genes in hBMSC-derived RPE cells following co-culture induction. A, the amount of some key transcriptional factors involved in RPE development were analyzed by real-time PCR and found to be present in hBMSCs-derived RPE cells (see Table 1). B, additional RPE cells-specific marker genes were determined by real-time PCR in hBMSCs-derived RPE cells. (mean \pm S.D., $\mathrm{n}=6$ independent experiments), $* \mathrm{P} \leq 0.01$, **P $\leq 0.05$.

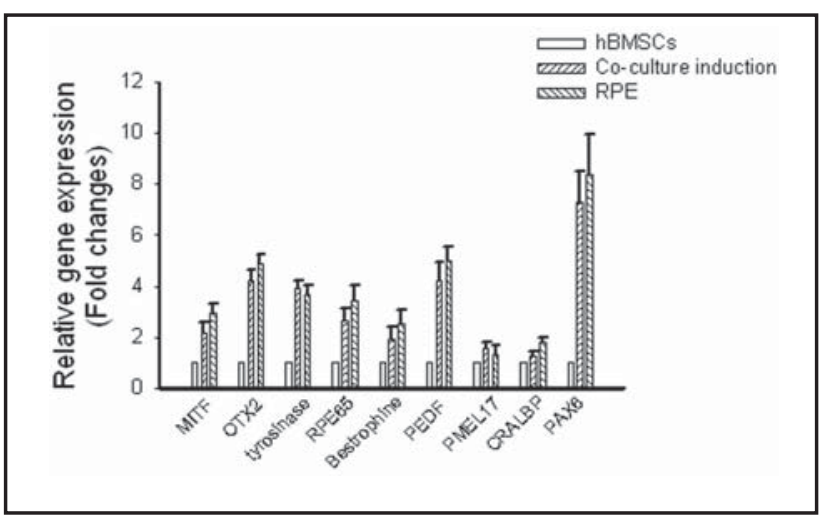

Fig. 4. The expression of some RPE marker proteins in hBMSCs-derived RPE cell. hBMSCs without induction, adult pig RPE and co-cultured cells were labeled by antibodies to CRALBP, RPE65 and ZO-1 and then examined by immunofluorescence. Cell nuclei were labeled with DAPI.

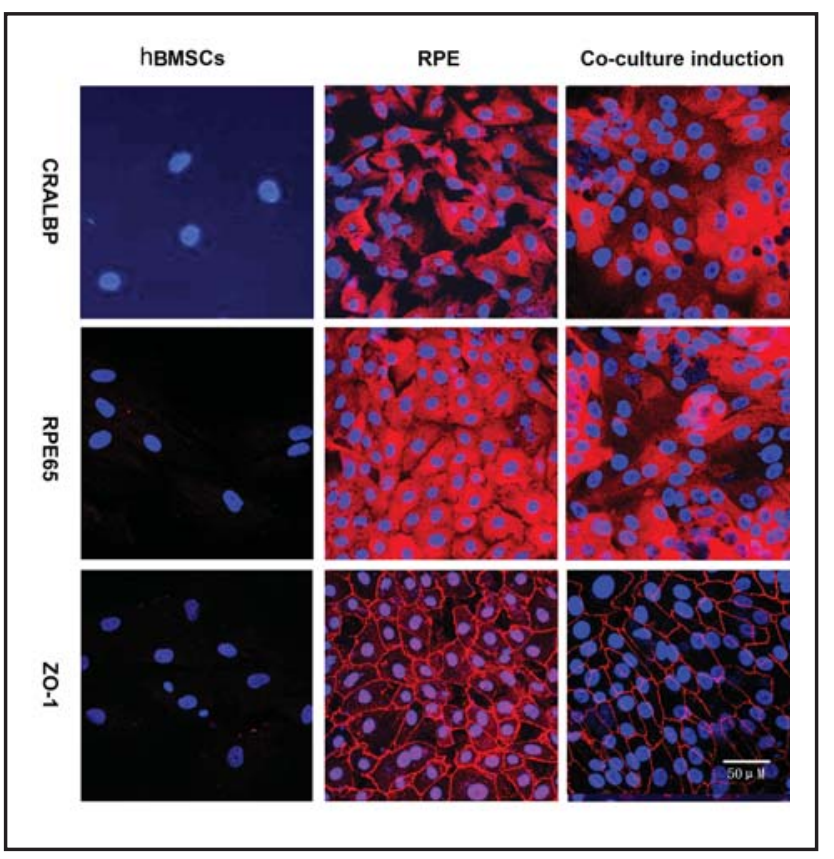

with control hBMSCs without co-culture induction (Fig. 3). PAX6 exhibited the highest upregulation in mRNA expression ( $\sim 7$-fold) (Fig. 3). Furthermore, the expression levels of the above genes in hBMSCs-derived RPE were comparable to those in freshly isolated adult RPE.

An immunofluorescence assay was used to assess the expression of typical RPE marker proteins in order to confirm that the increased gene expression led to changes in protein levels; these included CRALBP, RPE65 and ZO-1. The positive staining of these markers was observed in hBMSC-derived RPE cells when co-cultured with adult pig RPE for 14 days (Fig. 4).

\section{Phagocitic ability and neurotrophic secretion of hBMSCs-derived RPE cell}

hBMSCs-derived RPE cells were cultured with labeled POS to assess whether they had acquired some functional characteristics of RPE cells after co-culture induction. Green fluorescence was observed in both adult pig RPE cells and hBMSCs-derived RPE cells after $24 \mathrm{~h}$ in culture suggesting these cells had acquired the ability to phagocytose extracellular elements of the POS (Fig. 5A and B). Green fluorescence was not observed in the non-induced hBMSCs.

To determine if the phagocytic ability of hBMSCs-derived RPE cells is specific, we first determine the expression changes in MERTK and $\alpha \mathrm{V} \beta 5$ Integrin by Western blotting 


\section{Cellular Physiology and Biochemistry}

Fig. 5. The phagocytotic abilities of hBMSC-derived RPE cells. hBMSCs, RPE cells, and hBMSCs-derived RPE were exposed to photoreceptor outer segments labeled with FITC $(1 \times 107$ POS $/ \mathrm{ml})$ 24 hours. A, labeled POS was seen in the cultures adult pig RPE cells and co-culture induced hBMSCs but in uninduced hBMCSs (Olympus IX71 fluorescence microscope combined with DIC). B, Z-stack fluorescent images and crosssection side views to show the location of pigment granules and phagacytosed labeled POS debris: $\mathrm{x}-\mathrm{z}$ and $\mathrm{y}-\mathrm{z}$ showing location of fluorescence. Nuclei were counterstained with DAPI (blue). C, western blotting analysis of MERTK and $\alpha \mathrm{V} \beta 5$ Integrin in induced hBMSCs after 14-day coculture and hBMSCs without co-culture induction. Bar graphs are derived from densitometric scanning of the

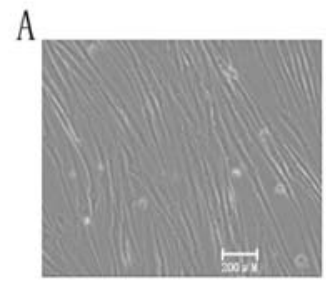

hBMSCs

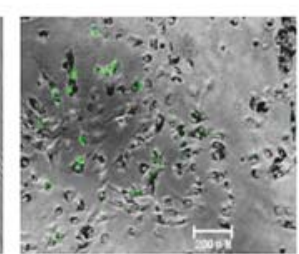

RPE

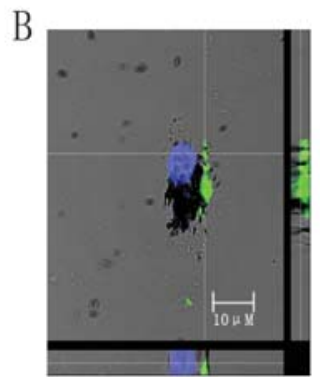

RPE

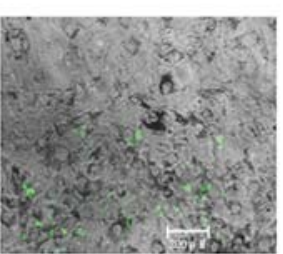

Co-culture induction

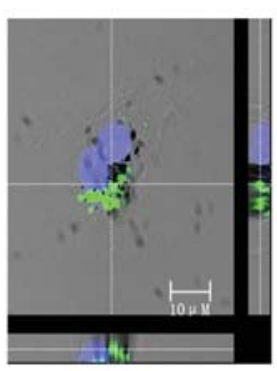

Co-culture induction

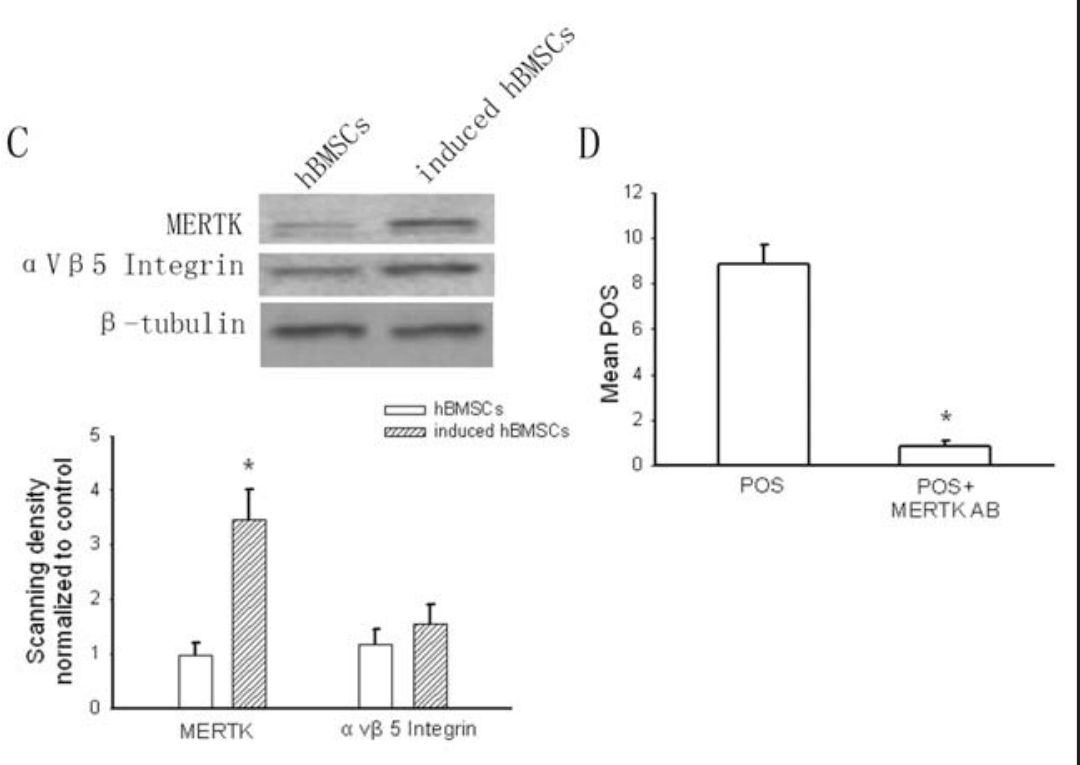

blots. Bars are mean \pm S.D. from three independent experiments. *Significantly different from non-induced hBMSCs control, $\mathrm{P}<0.05$. D, to determine the importance of MERTK in the phagocytosis of POS, we treated induced hBMSCs with MERTK antibody for 1 hour. Then these cells were exposed to POSs labeled with FITC $(1 \times 107 \mathrm{POS} / \mathrm{ml})$ for 24 hours. Finally, these cells were treated with trypan blue, washed, and fixed. The number of internalized POS was then quantified per field view $(150 \mu \mathrm{m} \times 150 \mu \mathrm{m})$.

according to another report [31]. After 14-day co-culture, the expression of MERTK in induced hBMSCs was significantly enhanced as compared with hBMSCs without co-culture induction. Meanwhile, the expression of $\alpha \mathrm{V} \beta 5$ Integrin was also enhanced, but not obviously (Fig. 5C). To examine the role of MERTK in phagocytosis by hBMSCs-derived RPE cells, we used a MERTK antibody to block receptor function. hBMSCs-derived RPE cells exposed to MERTK antibodies showed a significant reduction in the number of POS ingested over a $5 \mathrm{~h}$ period compared to control cells (Fig. 5D). These results suggest that the phagocytic ability of hBMSCs-derived RPE cells is specific and mostly dependent on MERTK. 
Fig. 6. The neurotrophic factors including BNDF (A) and GNDF (B) secreted by hBMSCs-derived RPE cells were examined by ELISA assay. Bars are mean \pm S.D. from four independent experiments. A, there is significant difference between every two groups. $\mathrm{B}$, there is significant difference between every two groups except between medium and hBMSCs groups.

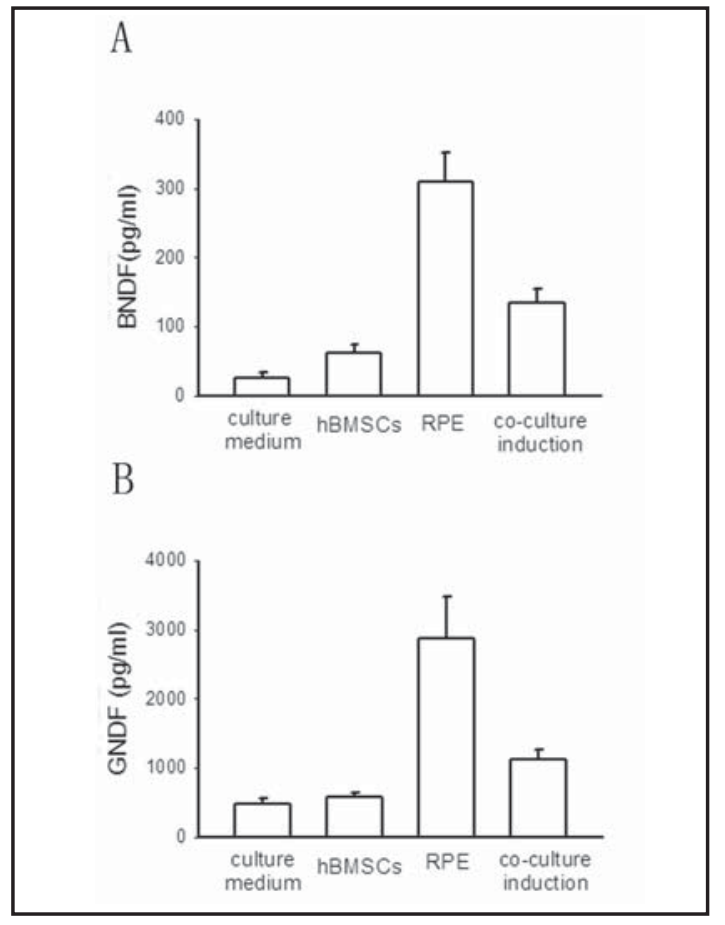

The results from the ELISA assay showed that there was significant enhancement of BDNF ( 2-fold, $n=6, p \leq 0.01$; Fig. 6A) and GDNF ( 2-fold, $n=6, p \leq 0.01$; Fig. 6B) in hBMSCderived RPE, relative to hBMSCs without co-culture induction. However, these values were significantly less than the values seen for the porcine RPE samples.

\section{Discussion}

The results of the present study showed that simply by co-culturing with primary isolated porcine RPE cells in a non-contact transwell system, hBMSCs can differentiate into RPE-like cells. These hBMSC-derived RPE cells showed typical intracellular pigment granules, expressed the cell markers of RPE cells, such as CRALBP, RPE65 and ZO-1, secreted the trophic factors of RPE cells, and obtained the ability of POS phagocytosis. Our data suggest that by mimicking part of the microenvirement of cell differentiation, hBMSCs can activate the expression of RPE-development related genes and differentiate into RPE-like cells.

Ithas been reported that BMSCs can differentiateinto neural-like cells and photoreceptors by co-culturing with RPE. For example, Yang et al. reported that human BMSCs differentiated into neural-like cells expressing special neuronal markers, and the expression of these markers was significantly increased by co-culturing with a bovine retinal extract [32]. Chiou et al. found that co-culturing with RPE and subsequent culturing with a neurogenic selection medium for two weeks facilitated the photoreceptor-lineage differentiation of hBMSCs [22]. BMSCs were also shown to differentiate to photoreceptor-like cells in an in vitro model by RPE-conditioned medium treatment [33]. BMSCs were prepared using paramagnetic beads for lineage depletion as well as for negative CD45 selection [33]. It is suggested from these studies that the different differentiation lineage of BMSCs by co-culturing with RPE may be derived from distinct pre-treatment of BMSCs and culture conditions. In the present study, however, we found that hBMSCs differentiated into the RPE-like cells by co-culturing with the primarily isolated pig RPE in a non-contact transwell system. In addition, the expression 


\section{Cellular Physiology and Biochemistry}

Cell Physiol Biochem 2013;31:601-613

DOI: $10.1159 / 000350080$

Published online: May 02, 2013

C) 2013 S. Karger AG, Basel

www.karger.com/cpb

611

Duan/Xu/Zeng/Wang/Yin: Transwell Co-Culture Induces RPE Differentiation of BMSCs

of the neuronal marker (MAP-2) was detectable in the differentiated BMSCs reported by Lecaude, which means that direct contact culture induction may result in part differentiation to neuronal cells of BMSCs [33]. However, MAP-2 was not detectable in hBMSCs-derived RPE cells in our study (data not shown). Thus, combined with other reports, our results suggest that co-culturing with RPE in a non-contact transwell system may be more suitable to induce the RPE-specific differentiation of hBMSCs.

The transwell-based co-culture system has well been documented to study the differentiation of stem cells. Murdoch reported that hBMSCs underwent chondrogenic differentiation in transwell cultures [34]. Co-culture of human placenta-derived mesenchymal stem cells (hPMSCs) and neural cells successfully induces neural differentiation of hPMSCs using the Transwell co-culture system [34]. Furthermore, our colleagues Liu et al. showed that BMSCs expressed retinal neuron-specific phenotypic markers by retinal neuron co-culture using a transwell system [24]. This method provides a similar human microenvironment system for cell differentiation and can be utilized to explore the effects of cell secretion or substance metabolism on other cells. Besides, this method can minimize toxicity and some harmful reactions due to chemical reagents induction.

Previous studies have shown that hBMSCs adopt RPE-like characteristics in direct cellcell co-culture with hBMSCs in vitro $[18,19]$. However, these studies have not determined the typical RPE-like function of the hBMSCs-derived RPE cells. We found that after noncontact co-culturing with the primarily isolated pig RPE cells using a transwell system, hBMSC-derived RPE cells aquired phagocytotic functions, and secreted neurotrophic factors including BDNF and GDNF. These results indicate that the non-contact transwell systembased co-culturing with RPE can effectively facilitate the development of RPE-like function in the differentiated hBMSCs.

The retinal microenvironment contains many kinds of soluble cytokines including bFGF, which contribute to the differentiation of BMSCs towards multiple phenotypes including retinal cells $[24,35]$. Our findings suggest that the soluble factors in the co-culture system, rather than direct cell-to-cell contact with RPE are sufficient to facilitate the lineage differentiation of hBMSCs into RPE-like cells. The present study also raises the possibility that cell-to-cell co-culture system may produce more soluble factors or pose other stimuli responsible for differentiation of BMSCs into neural-like cells and photoreceptors. Therefore, the lack of cell-to-cell contact using the transwell system will enable us to determine which soluble factors account for the lineage differentiation of hBMSCs into RPE-like cells in future studies.

The present study demonstrates that co-culturing with RPE by a non-contact transwell system can effectively induce the RPE-lineage differentiation of hBMSCs. Because human ESCs can easily differentiate into RPE cells and appear safe, they have been developed in recent study to the stage of clinical trials [12] in the treatment of AMD and Stargadrts disease. However, considering the issue of immunological rejection associated with the clinical use of human ESCs, co-culturing the patient's BMSCs with human ESCs-derived RPE may be a potential way to solve these major obstacles.

\section{Disclosure Statement}

The authors declare no competing financial interests.

\section{Acknowledgements}

The authors thank Dr. T. Fitz Gibbon for comments on earlier manuscript drafts. This study was supported by National Natural Science Foundation of China (No.81130017) and National Basic Research Program of China (No. 2013CB967002). 


\section{Cellular Physiology and Biochemistry}

Cell Physiol Biochem 2013;31:601-613

\begin{tabular}{l|l}
\hline DOI: $10.1159 / 000350080$ & (c) 2013 S. Karger AG, Basel
\end{tabular}

Published online: May 02, $2013 \quad$ www.karger.com/cpb

Duan/Xu/Zeng/Wang/Yin: Transwell Co-Culture Induces RPE Differentiation of BMSCs

\section{References}

1 Delcourt C, Lacroux A, Carriere I: The three-year incidence of age-related macular degeneration: the "Pathologies Oculaires Liees a l'Age" (POLA) prospective study. Am J Ophthalmol 2005;140:924-926.

-2 Klein R, Klein BE, Knudtson MD: Frailty and age-related macular degeneration: the Beaver Dam Eye Study. Am J Ophthalmol 2005;140:129-131.

-3 Leske MC, Wu SY, Hennis A, Nemesure B, Yang L, Hyman L, Schachat AP: Nine-year incidence of age-related macular degeneration in the Barbados Eye Studies. Ophthalmology 2006;113:29-35.

4 Jones BW, Watt CB, Frederick JM, Baehr W, Chen CK, Levine EM, Milam AH, Lavail MM, Marc RE: Retinal remodeling triggered by photoreceptor degenerations. J Comp Neurol 2003;464:1-16.

5 Haruta M: Embryonic stem cells: potential source for ocular repair. Semin Ophthalmol 2005;20:17-23.

6 Kokkinaki M, Sahibzada N, Golestaneh N: Human induced pluripotent stem-derived retinal pigment epithelium (RPE) cells exhibit ion transport, membrane potential, polarized vascular endothelial growth factor secretion, and gene expression pattern similar to native RPE. Stem Cells 2011;29:825-835.

7 Levin LA, Ritch R, Richards JE, Borras T: Stem cell therapy for ocular disorders. Arch Ophthalmol 2004;122:621-627.

8 Singh MS, MacLaren RE: Stem cells as a therapeutic tool for the blind: biology and future prospects. Proc Biol Sci 2011;278:3009-3016.

-9 Tao YX, Xu HW, Zheng QY, FitzGibbon T: Noggin induces human bone marrow-derived mesenchymal stem cells to differentiate into neural and photoreceptor cells. Indian J Exp Biol 2010;48:444-452.

10 Eiraku M, Takata N, Ishibashi H, Kawada M, Sakakura E, Okuda S, Sekiguchi K, Adachi T, Sasai Y: Selforganizing optic-cup morphogenesis in three-dimensional culture. Nature 2011;472:51-56.

11 Nakano T, Ando S, Takata N, Kawada M, Muguruma K, Sekiguchi K, Saito K, Yonemura S, Eiraku M, Sasai Y: Self-formation of optic cups and storable stratified neural retina from human ESCs. Cell Stem Cell 2012;10:771-785.

-12 Schwartz SD, Hubschman JP, Heilwell G, Franco-Cardenas V, Pan CK, Ostrick RM, Mickunas E, Gay R, Klimanskaya I, Lanza R: Embryonic stem cell trials for macular degeneration: a preliminary report. Lancet 2012;379:713-720.

13 Nishida H, Nakayama M, Tanaka H, Kitamura M, Hatoya S, Sugiura K, Harada Y, Suzuki Y, Ide C, Inaba T: Safety of autologous bone marrow stromal cell transplantation in dogs with acute spinal cord injury. Vet Surg 2012;41:437-442.

14 Ohnishi H, Oda Y, Aoki T, Tadokoro M, Katsube Y, Ohgushi H, Hattori K, Yuba S: A comparative study of induced pluripotent stem cells generated from frozen, stocked bone marrow- and adipose tissue-derived mesenchymal stem cells. J Tissue Eng Regen Med 2012;6:261-271.

15 Barker RA, Widner H: Immune problems in central nervous system cell therapy. NeuroRx 2004;1:472-481.

16 Lund RD, Wang S, Klimanskaya I, Holmes T, Ramos-Kelsey R, Lu B, Girman S, Bischoff N, Sauvé Y, Lanza R: Human embryonic stem cell-derived cells rescue visual function in dystrophic RCS rats. Cloning Stem Cells 2006;8:189-199.

-17 Vossmerbaeumer U, Ohnesorge S, Kuehl S, Haapalahti M, Kluter H, Jonas JB, Thierse HJ, Bieback K: Retinal pigment epithelial phenotype induced in human adipose tissue-derived mesenchymal stromal cells. Cytotherapy 2009;11:177-188.

-18 Arnhold S, Heiduschka P, Klein H, Absenger Y, Basnaoglu S, Kreppel F, Henke-Fahle S, Kochanek S, BartzSchmidt KU, Addicks K, Schraermeyer U: Adenovirally transduced bone marrow stromal cells differentiate into pigment epithelial cells and induce rescue effects in RCS rats. Invest Ophthalmol Vis Sci 2006;47:41214129.

19 Li Y, Atmaca-Sonmez P, Schanie CL, Ildstad ST, Kaplan HJ, Enzmann V: Endogenous bone marrow derived cells express retinal pigment epithelium cell markers and migrate to focal areas of RPE damage. Invest Ophthalmol Vis Sci 2007;48:4321-4327.

20 Fuchs E, Tumbar T, Guasch G: Socializing with the neighbors: stem cells and their niche. Cell 2004;116:769778.

21 Spradling A, Drummond-Barbosa D, Kai T: Stem cells find their niche. Nature 2001;414:98-104.

22 Chiou SH, Kao CL, Peng CH, Chen SJ, Tarng YW, Ku HH, Chen YC, Shyr YM, Liu RS, Hsu CJ, Yang DM, Hsu WM, 


\section{Cellular Physiology and Biochemistry}

Cell Physiol Biochem 2013;31:601-613

\begin{tabular}{l|l}
\hline DOI: $10.1159 / 000350080$ & (c) 2013 S. Karger AG, Basel
\end{tabular}

Duan/Xu/Zeng/Wang/Yin: Transwell Co-Culture Induces RPE Differentiation of BMSCs

Kuo CD, Lee CH: A novel in vitro retinal differentiation model by co-culturing adult human bone marrow stem cells with retinal pigmented epithelium cells. Biochem Biophys Res Commun 2005;326:578-585.

-23 Song H, Stevens CF, Gage FH: Astroglia induce neurogenesis from adult neural stem cells. Nature 2002;417:39-44.

24 Liu DN, Yin ZQ Wu N, Wang YH, Chen LF: Rat bone marrow stromal cells express retinal phenotypic markers following different induction protocols. Ophthalmic Res 2009;41:186-193.

25 Dai F, Shi D, He W, Wu J, Luo G, Yi S, Xu J, Chen X: hCTLA4-gene modified human bone marrow-derived mesenchymal stem cells as allogeneic seed cells in bone tissue engineering. Tissue Eng 2006;12:25832590.

26 Huang YH, Lee TH, Chan KJ, Hsu FL, Wu YC, Lee MH: Anemonin is a natural bioactive compound that can regulate tyrosinase-related proteins and mRNA in human melanocytes. J Dermatol Sci 2008;49:115-123.

27 Giordano F, Bonetti C, Surace EM, Marigo V, Raposo G: The ocular albinism type 1 (OA1) G-protein-coupled receptor functions with MART-1 at early stages of melanogenesis to control melanosome identity and composition. Hum Mol Genet 2009;18:4530-4545.

28 Molday RS, Hicks D, Molday L: Peripherin: A rim-specific membrane protein of rod outer segment discs. Invest Ophthalmol Vis Sci 1987;28:50-61.

29 Liu B, Wang G, Yang J, Pan X, Yang Z, Zang L: Berberine inhibits human hepatoma cell invasion without cytotoxicity in healthy hepatocytes. PLoS One 2011;6:e21416.

-30 Huang C, Zhang J, Ao M, Li Y, Zhang C, Xu Y, Li X, Wang W: Combination of retinal pigment epithelium cellconditioned medium and photoreceptor outer segments stimulate mesenchymal stem cell differentiation toward a functional retinal pigment epithelium cell phenotype. J Cell Biochem 2009;113:590-598.

-31 Carr AJ, Vugler A, Lawrence J, Chen LL, Ahmado A, Chen FK, Semo M, Gias C, da Cruz L, Moore HD, Walsh J, Coffey PJ: Molecular characterization and functional analysis of phagocytosis by human embryonic stem cell-derived RPE cells using a novel human retinal assay. Mol Vis 2009;15:283-295.

-32 Yang LL, Zhou QJ, Wang Y, Wang YQ: Differentiation of human bone marrow-derived mesenchymal stem cells into neural-like cells by co-culture with retinal pigmented epithelial cells. Int J Ophthalmol 2010;3:2327.

-33 Hong Y, Xu GX: Proteome changes during bone mesenchymal stem cell differentiation into photoreceptorlike cells in vitro. Int J Ophthalmol 2011;4:466-473.

-34 Murdoch AD, Grady LM, Ablett MP, Katopodi T, Meadows RS, Hardingham TE: Chondrogenic differentiation of human bone marrow stem cells in transwell cultures: generation of scaffold-free cartilage. Stem Cells 2007;25:2786-2796.

-35 Klassen H, Sakaguchi DS, Young MJ: Stem cells and retinal repair. Prog Retin Eye Res 2004;23:149-181. 